\section{A TRANSDISCIPLINARIDADE NO ENSINO SUPERIOR EM CABO VERDE ${ }^{1}$}

\section{Jorge Sousa Brito*}

RESUmO: Razões históricas e geográficas fizeram de Cabo Verde, ao longo dos últimos cinco séculos, um lugar de confluência de civilizações e de experimentação/aclimatação dos mais diversos recursos e idéias. Isso se traduziu numa sociedade aberta ao mundo, numa economia de circulação e na personalidade universal do homem cabo-verdiano. Este posicionamento estratégico num mundo globalizado requer uma visão transdisciplinar do cidadão. $\mathrm{O}$ ensino superior é um veículo privilegiado para tal e, à luz das recomendaçōes da UNESCO, deve a transdisciplinaridade fazer parte da nova universidade do século XXI. O nascimento de uma universidade transdisciplinar em Cabo Verde parece algo muito natural. Essa universidade nasceu em 2001 (a Universidade Jean Piaget de Cabo Verde) e já desenvolve uma acção transdisciplinar e pesquisa direccionada nesse sentido. O contexto do ensino superior em Cabo Verde, porém, carece de maior atenção e a visão transdisciplinar seria mais do que necessária para uma educação liberal, em prol duma cidadania terrestre.

\section{Introdução}

O Homo Sapiens é parte integrante da Natureza e, como tal, com ela interage. Contudo, outras realidades, que não a da Natureza, têm sofrido, nos últimos anos, um desenvolvimento tão importante que o referido relacionamento Homem-Natureza se esbate no universo cada vez mais concorrencial dos relacionamentos Homem-Máquina e, mais recentemente, Homem-Mundo Virtual.

Essa questão começou a se tornar notória no fim dos anos oitenta do século passado, com a reviravolta no xadrez mundial (simbolizado pela queda do muro
Palavras-chave: transdisciplinaridade; ensino superior; Cabo Verde; Universidade Jean Piaget; educação liberal.

*Professor Catedrático e Vicereitor da Universidade Jean Piaget de Cabo Verde

${ }^{1}$ Nota do revisor: a revisão or tográfico-gramatical procurou manter a estrutura lingüística do original do português lusitano. 
de Berlim), o surgimento da chamada globalização, o desabrochar das então novas tecnologias da comunicação e informação e a vulgarização do computador pessoal. Alguns pensadores, atónitos com o rápido desenrolar dos acontecimentos, sentiram a necessidade de intervir, reuniram-se à volta desta problemática e convieram que uma outra abordagem da nova realidade, apelidada de complexa, era necessária. Nascia então um outro olhar (o da transdisciplinaridade), que não só iria lidar com a realidade complexa, como também se consciencializava do divórcio do homem em relação à Ciência e à Natureza, provocado pela aceleração sem precedentes do saber tecnológico e disciplinar (CAZENAVE; NiCOlESCU, 1994). A multiplicidade de disciplinas e de informações, patente no mundo actual, aliadas aos cada vez mais eficazes meios de comunicação e divulgação, trazem uma crescente desorientação ao indivíduo que não sabe lidar com elas e é levado a ter visões parcelares, seccionadas, descontextualizadas e inadequadas, da realidade complexa.

$\mathrm{O}$ estudo e o uso da transdisciplinaridade têm por finalidade a compreensão da realidade complexa do mundo actual, fazendo sua integração centrada no sujeito, e visando à unidade do conhecimento (NICOLESCU, 1996). Esse processo diz respeito ao que se encontra entre as disciplinas, através das disciplinas e para além de toda a disciplina (NICOLESCU, 1998). A metodologia transdisciplinar repousa sobre três pilares: os níveis de realidade, a lógica do terceiro incluído e a complexidade. A transdisciplinaridade é também considerada uma atitude integradora da experiência vivida e da sistematização do conhecimento organizado (as disciplinas), em direcção de um maior e crescente nível de lucidez (JUDGE, 1994).

A capacidade de lidar com o pensamento complexo (MoRIN, 1990) torna-a recomendável nas estruturas e programas da universidade do novo século. A UNESCO cedo se interessou pelo pensamento transdisciplinar e, em 1997, apoiou o CIRET (Centre International de Recherches et Études Transdisciplinaires) na realização, em Locarno, dum congresso internacional sobre o tema "Quelle Université pour demain? Vers une évolution transdisciplinaire de l'Universitế. A questão do pensamento complexo voltou a ser abordada numa perspectiva de ponte entre a transdisciplinaridade e o ensino superior (MORIN, 1997). Os resultados e recomendações desse congresso inspiraram alguns artigos 
da Déclaration Mondiale e do Cadre d'Action Prioritaire ${ }^{3}$ saídos da Conferência Mundial sobre o Ensino Superior que teve lugar em Paris, de 5 a 9 de Outubro de 1998. Neste particular, uma das vocaçôes da transdisciplinaridade é a procura das medidas necessárias para adaptar a universidade ao espaço cibernético das novas tecnologias da informação e da comunicação (GIBBONS, 1998).

Essa partilha universal dos conhecimentos e saberes, à luz das novas correntes patenteadas nas referidas conferências de Locarno e Paris, não pode passar ao lado duma nova tolerância fundada na atitude transdisciplinar que, na prática, está orientada por uma visão transcultural, transpolítica, transreligiosa e transnacional. Não podemos, pois, contornar a relação directa entre paz e transdisciplinaridade.

\section{Os primeiros passos da transdisciplinaridade em Cabo Verde}

A coabitação de vivências e experiências diversas, de saberes e culturas distintas e o confronto, entrechoque e integração dessas e destes fizeram com que, em Cabo Verde, a transdisciplinaridade encontrasse há muito um terreno fértil. Efectivamente o povo cabo-verdiano é, na sua vivência e génese, um paradigmático exemplo do exercício transdisciplinar (BRITO, 2000-a). Razões históricas e geográficas fizeram de nosso país, ao longo dos últimos séculos, um lugar de confluência de civilizações e de culturas e um autêntico caldeirão onde se forjou esta vivência 'trans...'. Vejamos algumas dessas particularidades:

- Simultânea e propositadamente Cabo Verde foi utilizado como campo de experimentação e aclimatação de novas essências vegetais e de animais trazidos da África e da Ásia antes da sua introdução nas Américas e na Europa;

- O tráfico e o comércio de escravos requeriam a chamada ladinizaçãó $o^{4}$ de muitos deles para poderem servir de copeiros, amas, mordomos, cozinheiros e outras funções mais mundanas do que a de simples trabalho braçal;

- A multiplicidade de etnias africanas entre os escravos confinados provocou uma troca de experiências ímpar e a formação paulatina de um sentimento de solidariedade e de uma capacidade de transmissão de ideias e de pensamentos

\begin{abstract}
${ }^{2} \mathrm{Art}{ }^{\mathrm{O}} 5$ (a) "L'innovation, l'interdisciplinarité et la transdisciplinarité devraient être encouragées et renforcées dans les programmes, avec des orientations à long terme vers des objectifs et des besoins sociaux et culturels...". Arto 6(b) - "Lenseignement supérieur doit renforcer ses fonctions de service de la société, en particulier ses activités visant à éliminer la pauvreté, lintolérance, la violence, l'analphabétisme, la faim, la dégradation de l'environnement et la maladie, par une approche interdisciplinaire et transdisciplinaire de l'analyse des problèmes et des enjeux".
\end{abstract}

${ }^{3}$ Arto 6 - "Lorsquils arrêtent des priorités dans leurs programmes et leurs structures, les établissements d'enseignement supérieur devraient: a) tenir compte du respect de l'éthique, de la rigueur scientifique et intellectuelle ainsi que de l'approche multidisciplinaire et transdisciplinaire".

${ }^{4}$ Este termo se refere ao acto de 'tornar ladino' os escravos, ou seja, fazer com que tenham mais discernimento e se adaptem aos usos e costumes dos donos. 
${ }^{5}$ Carlos Bellino Sacadura e Jorge Sousa Brito. por processos não-verbais ou por uso, na comunicação verbal, de onomatopeias e metáforas sugestivas - nasce o Pidjin e mais tarde o crioulo;

- A desertificação e as secas levaram à emigração sistemática do povo caboverdiano. As diferentes paragens em que o cabo-verdiano se encontra, aliadas à sua tradicional vontade em regressar à terra, propiciam um vaivém de saberes e de informações extraordinário. Nisto podemos dizer que a globalização chegou a Cabo Verde desde o início do século XIX.

Antes mesmo da recomendação da UNESCO, já o ensino superior em Cabo Verde contava com dois dos seus docentes envolvidos em lides transdisciplinares, ${ }^{5}$ os quais tiveram o privilégio de participar do $1^{\circ}$ Colóquio Mundial sobre a Transdisciplinaridade, realizado na Arrábida, Portugal, em 1994. Estes únicos participantes do continente africano estão entre os subscritores da Carta da Transdisciplinaridade, aprovada nesse colóquio.

A aplicação e divulgação do pensamento transdisciplinar no ensino passaram a ter nestes referidos docentes seus principais defensores. Por exemplo, o ensino da Química foi objecto de pesquisa transdisciplinar, resultando numa diferente didáctica (BRITO, 1994; 1996).

\section{Breve historial do ensino superior em Cabo Verde}

A entrada de Cabo Verde no círculo das Naçōes, em 1975, trouxe naturalmente um vasto leque de preocupaçôes atinentes ao desenvolvimento, sendo a formação de quadros um dos principais vectores. Com efeito, um número relativamente elevado de estudantes tem freqüentado, em vários países, cursos de áreas científicas as mais diversas.

Devido a uma falta de articulação entre a formação e as necessidades do país, uma parcela não negligenciável de bolseiros no exterior adquiriu formação em áreas não prioritárias, ou formação pouco adequada à nossa realidade. Por outro lado, à formação local foi dada pouca atenção e o seu fraco prestígio foise agravando com a matrícula de estudantes que não puderam obter bolsa para o exterior, logo os menos habilitados. 
Uma análise histórica do ensino superior em Cabo Verde mostra que as iniciativas no sector surgiram sempre como resposta a situaçôes conjunturais muitas vezes anunciadoras de crise:

- Logo após a Independência, era flagrante a carência de quadros para o desenvolvimento: dever-se-ia formar o maior número possível e nas mais diversas áreas. Foram solicitadas bolsas a instituiçōes e países amigos, os quais acudiram prontamente. Não tínhamos candidatos suficientes para preencher as vagas oferecidas, fazendo-se necessário fomentar o ensino secundário, o que se traduziria em sua manifestação e no rebaixamento do nível académico dos professores recrutados. A situação era de tal ordem preocupante que a única solução para o 'abastecimento' de professores secundários, em número e com qualificação suficiente, foi a de abrir no país o Curso de Formação de Professores do Ensino Secundário (1979).

- O combate à erosão, a necessidade de protecção vegetal, melhoramento das culturas e outras actividades agrícolas e agrárias cedo gritaram por técnicos profissionais e médios, levando o país a abrir, em 1982, o Centro de Formação Agrária de São Jorge.

- Uma das linhas de força do $1^{\circ}$ Plano Nacional de Desenvolvimento era a do aproveitamento da posição geoestratégica do país no tocante ao desenvolvimento da marinha mercante, das frotas de pesca e da construção naval. O crescimento das frotas e os estaleiros da empresa Cabnave ditaram a criação, em 1984, do Centro de Formação Náutica.

- Com a extroversão da economia cabo-verdiana e o aumento da margem de manobra das empresas no âmbito das transformaçōes internacionais e nacionais do início da presente década, o tecido empresarial, ciente das perspectivas que se abriam, resolve criar, em 1992, cursos na área de Gestão \& Marketing e na de Contabilidade.

- Começa-se a sentir os efeitos negativos da massificação do ensino: o nível académico dos candidatos a bolsa é fraco e o número deles é assustador. Criase então o Curso Propedêutico (ano vestibular), que iria dar uma melhor preparação aos referidos candidatos e, ao mesmo tempo, seria um instrumento de contenção. 
- O desenvolvimento de Cabo Verde engendrou índices socioeconómicos que o descartavam dos intervalos clássicos tidos como referência por países doadores. Uma das consequências tem sido uma nítida diminuição, pelos doadores, do número de bolsas e das áreas em que eram oferecidas. Por outro lado, o Ano Zero (curso vestibular reforçado que substituiu o Propedêutico) já não tem o seu efeito tampão, tal o número de alunos que obedecem aos critérios de entrada nesse ano. As bolsas passaram a ser reembolsáveis e Cabo Verde negocia vagas nas universidades de países lusófonos (poupa-se o ano de aprendizagem de língua).

Sendo notória a carência de quadros superiores profissionalizados, não seria mais uma vez a criação de cursos superiores no país solução miraculosa? As áreas seriam escolhidas em razão das prioridades (as mais carentes) e das disponibilidades (os recursos mais facilmente mobilizáveis - o que geralmente se traduz no desdobramento e na sobreutilização dos existentes, com subsequente perda de qualidade).

Se repararmos bem, toda esta abordagem tem sido baseada na premissa de que o ensino superior é condicionado pelo desenvolvimento. Esta política de 'tapa buracos', panaceia das crises, é bastante redutora. É certo que os novos cursos alimentam o desenvolvimento, mas a perspectiva é mais de fruto do que de motor do desenvolvimento. Esta postura, além de estagnadora, é incompleta e frágil. É de notar que o objectivo principal desses cursos era formar quadros e que não houve a preocupação real (não cosmética) de neles integrar as componentes investigação e extensão.

Entretanto as impressionantes mudanças deste fim de milénio e o recente estádio de desenvolvimento de Cabo Verde trazem um certo número de desafios que apelam para uma cuidada reflexão onde não se pode descurar nenhum sector interveniente. É necessário que o ensino superior se torne motor do desenvolvimento. Efectivamente os problemas da modernização e do correcto rumo ao adequado posicionamento do país no mapa da 'aldeia global' levam a que se considere o desenvolvimento do ensino superior um sector de importância estratégica, ou seja, condicionante do desenvolvimento. Com base no reconhecimento deste papel, os governos da II República consideraram prioritária, para o sector da educação, a criação de condições para a institucionalização do ensino superior. 
Assim, em 1991 foi criada a Comissão Instaladora do Ensino Superior, que teve por tarefa equacionar as primeiras medidas conducentes à consolidação deste nível de ensino, impregnar as iniciativas de formação em curso de um cunho mais académico e de um espírito mais consentâneo com o paradigma tridimensional do ensino superior: formação-investigação-extensão.

É deste modo que, a partir dos cursos e centros existentes, vêm nascendo Institutos Superiores dotados de autonomia científica, pedagógica, administrativa, financeira e patrimonial: O Instituto Superior de Educação (1995), o Instituto Superior de Engenharia e Ciências do Mar (1996) e o Instituto Superior de Ciências Económicas e Empresariais (1998).

Obedecendo às novas linhas de orientação, o subprograma do Governo para o desenvolvimento do ensino superior, comporta três objectivos principais: 1. Institucionalizar e consolidar o ensino superior;

2. Desenvolver o ensino superior na óptica da criação de uma capacidade endógena em ciência \& tecnologia;

3. Articular as actividades do ensino superior e da investigação \& desenvolvimento.

A realização conjunta destes objectivos visa atingir, a curto e médio prazos, as seguintes metas:

- Funcionamento da Universidade de Cabo Verde;

- Constituição de um colectivo de quadros altamente qualificados;

- Inversão das actuais taxas de formação superior do país (20\%) versus as do exterior (80\%);

- Funcionamento das leis reguladoras do ensino superior

Para melhor conduzir esta política, o Governo extinguiu a Comissão Instaladora do Ensino Superior e criou, em 1997, a Direcção Geral do Ensino Superior e Ciência.

\section{O respeito em Cabo Verde da recomendação da UNESCO}

No ano seguinte à Conferência Mundial sobre o Ensino Superior, foi realizado na cidade da Praia um fórum sobre o ensino superior em Cabo Verde. Uma das recomendações saídas deste fórum foi o enfoque transdisciplinar do ensino e uma visão globalizante entre as ciências exactas e as sociais. 
Os trabalhos conducentes à criação da Universidade de Cabo Verde fizeram constar da proposta de lei que a instituiria alguns princípios nos quais, embora não estivesse explícita a questão transdisciplinar, esta podia ser pressentida:

- A Universidade de Cabo Verde (U.C.V.) é um centro de criação, transmissão e difusão da cultura, da ciência e da tecnologia que, pela articulação entre estudo, docência, investigação e prestação de serviços, constitui um instrumento estratégico do desenvolvimento do país;

- A U.C.V. está aberta ao mundo contemporâneo, à cooperação entre os povos e interacção das culturas, no respeito pelos valores da independência, da tolerância e do diálogo.

A criação de uma universidade transdisciplinar em Cabo Verde foi igualmente objecto de uma comunicação (BRITO, 2000a) na qual, mais do que uma recomendação, demonstrava-se sua natural e inexorável pertinência. Entretanto, apesar dessas recomendações, a criação da universidade pública de Cabo Verde ainda não se efetivou. Em contrapartida, uma universidade privada de foro associativo e caráter transdisciplinar, de jure e de facto, foi criada em 7 de Maio de 2001: a Universidade Jean Piaget de Cabo Verde.

\section{A Universidade Jean Piaget de Cabo Verde e a transdisciplinaridade}

O surgimento da Universidade Jean Piaget de Cabo Verde (UniPIAGET) veio dar resposta ao apelo feito sobre a necessidade de uma universidade transdisciplinar em Cabo Verde. Ao que parece, ela é a primeira na região oesteafricana a ter um cariz transdisciplinar.

A UniPiaget foi instituída pelo Instituto Piaget, instituição portuguesa que já tem, na sua prática de longos anos, a postura transdisciplinar. Além de realizar pesquisa no âmbito da transdisciplinaridade, por meio do CIERT (Centro Internacional de Estudo e Reflexão Transdisciplinar), promove conferências sobre o tema e detém uma produção editorial da qual fazem parte obras de autores transdisciplinares como Edgar Morin. A transdisciplinaridade é presente na UniPiaget e tem-se manifestado sob vários aspectos, características, programas e acções, como veremos a seguir. 


\section{- nos Estatutos}

O pensamento transdisciplinar é consagrado nos estatutos da universidade, por intermédio do seguinte articulado: "A UniPiaget de Cabo Verde é uma estrutura social educativa destinada à criação, desenvolvimento, transmissão e difusão da Cultura, nomeadamente das artes, técnicas, ciências e demais saberes, numa perspectiva intercultural e transdisciplinar”.

\section{- nos Planos Curriculares}

Além do cuidado habitual em harmonizar os planos curriculares de modo a conferir um equilíbrio contextual às disciplinas mestras de um determinado curso, todos os cursos da UniPiaget possuem um seminário obrigatório de Antropologia, que visa a oferecer aos estudantes a oportunidade de adquirir uma sensibilidade especial que lhes permita descobrir a complexidade das sociedades humanas e, concomitantemente, perceber a diversidade sempre presente na unidade, eliminando possíveis discriminações ou exclusões na comunidade onde vierem, profissionalmente, a inserir-se.

\section{- na Pesquisa}

Atendendo às recomendações da UNESCO, é de se esperar que uma universidade forme um cidadão que tenha visão e pensamento transdisciplinares. Criar uma disciplina por meio da qual se ensine a transdisciplinaridade choca um pouco com o facto de esta problemática extravasar as disciplinas. À guisa de uma "pescadinha com o rabo na boca, fractal”" perguntar-se-á: "O que dirá respeito ao que se encontra entre as disciplinas, através das disciplinas e para além da disciplina Transdisciplinaridade?”.

Certamente, torna-se mister organizar uma célula de pesquisa para desenvolver os métodos que possam transformar o aluno que entra na universidade nesse cidadão transdisciplinar, sem que haja uma disciplina que estude a transdisciplinaridade. É então que se desenvolve, na Universidade Jean Piaget de Cabo Verde, uma linha de pesquisa com esse objectivo. Em vez de uma disciplina, aperfeiçoou-se um módulo que, desde 1999, vem sendo dado na Universidade de Évora pelos dois docentes já mencionados, agora também
${ }^{6} \mathrm{~A}$ pescadinha é um peixe que, em Portugal, se vende dobrado em forma de arco. Isso se consegue fazendo com que o rabo do peixe seja inserido em sua boca. $\mathrm{O}$ adágio popular evoca esta imagem para ilustrar os ciclos viciosos. A referência fractal insere este ciclo vicioso numa mudança de escala sucessiva, contendo cada ciclo os ciclos anteriores. 
docentes da Universidade Jean Piaget de Cabo Verde. Esse módulo insere-se na disciplina Teoria Geral dos Fenómenos e Epistemologia Comparativa, ministrada no Mestrado em Ecologia Humana desta Universidade. Deste modo, a UniPiaget insere-se na cooperação interuniversitária, mas no sentido Sul-Norte.

Com base nesse módulo e na experiência vivida ao ministrá-lo, pretendese criar um pequeno curso em que abordagens e práticas conducentes a um descortínio de caminhos para um maior grau de lucidez e discernimento serão o fio condutor principal. Este curso transdisciplinar será um trunfo precioso que preparará o formando para melhor lidar com os principais flagelos do complexo mundo moderno. Problemáticas como a da droga, da AIDS, do desemprego e da insegurança pelo terrorismo inspirado em fundamentalismos podem ser atacadas com maior eficácia em abordagens transdisciplinares. A criação de um ambiente propício ao exercício da transdisciplinaridade na universidade parece ser uma das formas mais eficazes de atingir o objectivo em vista. Neste particular, deve a universidade privilegiar três eixos de actuação:

- Fomentar a pesquisa transdisciplinar na vertente reflexão e na da metodologia para uma educação transdisciplinar;

- Criar sinergias entre disciplinas, actividades extracurriculares, integração na sociedade e interacção com ela, inspiradas para a promoção da interculturalidade e da educação para a paz;

- Trazer para o seio da universidade as problemáticas acima mencionadas, a fim de serem objecto de estudo, debate, pesquisa e de programas integrados de combate e luta.

\section{- nas Actividades e Acçóes}

Com base nesses eixos de actuação, a Universidade Jean Piaget de Cabo Verde tem nestes dois anos promovido e realizado as actividades e acçóes seguintes:

- Semanas temáticas - são semanas em que uma área científica patente na universidade é posta a nu com a realização de conferências, exposições, mesas redondas, debates, apresentação de trabalhos, venda de livros etc. Já se realizaram as semanas de Economia, Informática, Saúde, Sociologia, Psicologia, Arquitectura e Engenharia da Construção Civil; 
- Inscrição em associações universitárias internacionais - a Universidade Jean Piaget de Cabo Verde já é membro da AulP (Associação das Universidades de Língua Portuguesa), da AUA (Association des Universités Africaines) e do Fórum UNESCO Universidade e Património;

- Albergar e ser sede regional de organizaçôes e iniciativas internacionais em domínios próximos dos objectivos visados - podem-se citar a Cisco Systems Incorporation e o referido Fórum UNESCO, cujas sedes regionais já se encontram instaladas na UniPiaget;

- Adesão ao projecto regional de inserção da SIDA nos currículos das universidades francófonas africanas;

- Promoção da temática empregabilidade ${ }^{7}$ no seio da massa estudantil, bem como o cuidado da abertura de cursos com variantes adequadas às necessidades do país e do mercado de trabalho. Pensa-se promover os chamados 'ninhos de empresas', ou seja, a universidade ajuda os estudantes a criar e organizar as suas empresas e deixa de as albergar logo que estejam aptas a caminharem sozinhas.

Embora seja um grande passo o surgimento de uma universidade transdisciplinar em Cabo Verde, a UniPiaget não poderá cabalmente desempenhar este papel se não houver uma política de ensino superior consentânea com esse desiderato. É nesse sentido que se torna mister discorrer sobre uma visão transdisciplinar para o ensino superior em Cabo Verde.

\section{Uma visão transdisciplinar para o ensino superior em Cabo Verde}

Para além do cumprimento das recomendações da UNESCO no que concerne à transdisciplinaridade nas universidades, o que daria na criação de universidades públicas transdisciplinares, o Estado deveria ir mais longe e adoptar uma visão transdisciplinar em sua política de ensino superior.

A caracterização do que deve ser o ensino superior em países como Cabo Verde requer uma visão clara da situação nacional num futuro a curto, mas, sobretudo, a médio prazo. Se os contornos desse sistema dependem do que se
${ }^{7}$ Entende-se este termo no sentido da potenciação das chances de encontrar emprego e/ou auto-emprego, por meio das características mais adequadas da própria formação. 
prevê para o país no futuro (visão do ensino superior como 'fruto' do desenvolvimento), não é menos certo que esse retrato não poderá concretizar-se sem um ensino superior dinâmico e coerente (visão do ensino superior como 'motor' do desenvolvimento) (BRITO, 1997). Cenários catastróficos para os países em desenvolvimento que não cuidarem convenientemente do seu ensino superior são vaticinados por peritos mundiais em educação e em economia. A nossa situação será muito pior se não forem tomadas agora as proveniências necessárias para um sistema coerente de ensino superior em Cabo Verde. Não estamos a falar de um certo número de receitas para atingir um determinado fim: a questão é mais complexa, uma vez que o novo paradigma da economia mundial muda constantemente à medida que a fonte principal de riqueza deixa de ser o capital físico, para ser o do conhecimento. Hoje em dia, a riqueza está cada vez menos centrada na terra, nas máquinas ou nas fábricas; o conhecimento e a capacidade pericial dos indivíduos são, sim, mais críticos para a economia mundial. A tecnologia está a ser um motor deste processo pelo uso das tecnologias da informação (da Internet ao virtual) e da biotecnologia (dos transgénicos à clonagem) que lideram as mudanças, talvez mutaçôes, no nosso modo de viver.

A consciência de que a incremento do ensino superior nos países em desenvolvimento constituiu uma prioridade de topo, sem a qual se torna inexorável um agravamento irreversível das disparidades e um aumento da pobreza, é coisa recente. A seguir à Conferência Mundial sobre o Ensino Superior no Século XXI (Paris, 1998), a UNESCO e o Banco Mundial formaram uma equipa de peritos altamente qualificados, de 13 países, para explorarem o futuro do ensino superior nos países em desenvolvimento. Após dois anos de trabalho, produziram um relatório intitulado $O$ Ensino Superior nos Países em Desenvolvimento: Perigos e Esperanças (THE World BANK, 2000). Nele abordam temas interessantes e pertinentes e realçam a necessidade urgente da organização e desenvolvimento do ensino superior nesses países.

$\mathrm{O}$ ensino superior tem vindo a confrontar com o que se pode designar de 'novas realidades' como a expansão e a diferenciação.

O problema da expansão refere-se à crescente procura do ensino superior por parte daqueles que saem do secundário, e esta situação em Cabo Verde foi 
alvo de uma chamada de atenção (BRITO, 2001). A pressão é tão grande que as autoridades se vêem confrontadas com vários dilemas: Que fazer? Fechar a porta de saída do secundário? Abrir completamente as do superior? Mas que porta? A do exterior? Com que meios? Bolsas? A porta do ensino superior local? Cabem todos? Que ensino superior local? Desenvolvê-lo? E a que preço? Com que objectivos? Criar liceus de adultos?

Põe-se o problema do acesso! Deve ele ser livre ou condicionado? Se condicionado, com que critérios e objectivos? Usar filtros? Que filtros? Para limitar o número? Para melhor distribuição pelas instituiçôes? Estas são questôes que urge clarificar.

Sendo clara a recomendação da UNESCO, aquando da referida Conferência Mundial, de que o acesso ao ensino superior deve ser democrático, para todos e baseado no mérito, e ainda mais forte a de que se deva desenvolver e incentivar a formação superior em países como o nosso, torna-se legítimo que todo jovem aspire a este nível de formação. É saudável e salutar que assim seja e deve-se fazer tudo para que as portas lhe sejam abertas para tal - é um direito do cidadão!

Alguns países adoptaram o figurino de absorver, no seu sistema público de ensino superior, toda a massa estudantil, o que resultou em megauniversidades (a do México, por exemplo, tem 200.000 estudantes). Outros países permitiram a chamada 'diferenciação', ou seja, o nascimento de estabelecimentos de ensino superior diversos em índole, figurinos e objectivos, vindo a dar resposta a todo tipo de solicitação e aspiração. Esta diferenciação, quando bem conduzida, leva a excelentes resultados.

Fala-se também em 'diferenciação horizontal' - trata-se dos diferentes tipos de provisão e financiamento do ensino superior (relacionados com o aumento da procura), a saber:

- Estabelecimentos de ensino superior públicos;

- Estabelecimentos de ensino superior privados com fins não lucrativos (ou filantrópicos);

- Estabelecimentos de ensino superior privados com fins lucrativos;

- Ensino superior a distância.

Recomenda-se a 'diferenciação vertical' - motivada por uma reaç̧ão à 
procura de uma diversidade no tipo de formados, constituída de vários tipos:

- Universidade de investigação;

- Institutos universitários (regionais ou provinciais);

- Escolas profissionais (politécnicos);

- Escolas vocacionais (paralelas ao ensino secundário/superior) não são consideradas muitas vezes como componentes do ensino superior.

Ora, Cabo Verde está a enveredar para um sistema de diferenciação. Mas urge equilibrar e ter uma política de ensino superior bem definida. $\mathrm{O}$ sistema diferenciado pressupóe um ensino superior público consistente que possa fazer parte do sistema em posição de competir a bem do chamado interesse público, que, por sua vez, relaciona-se com o desenvolvimento económico e social, concentrando-se na capacidade do ensino superior para:

- desbloquear o potencial de todos os níveis da sociedade;

- criar uma cadeia de indivíduos altamente formados;

- esclarecer tópicos com valor a longo prazo para a sociedade;

- fornecer um espaço de discussão livre e aberta de ideais e valores.

Esta capacidade será reforçada se forem igualmente adoptadas as recomendaçōes da UNESCO em matéria de transdisciplinaridade.

Considerando o sistema de ensino superior que se propóe, multifacetado e baseado na chamada diferenciação, torna-se importante a questão do acesso.

A nosso ver (BRITO, 2000b), não se devem colocar barreiras quantitativas (numerus clausus, testes orientados para eliminar candidatos), e sim proceder a uma selecção qualitativa. Não se trata de ter o aluno com melhores notas (isto resultaria em teste eliminatório, logo em filtro quantitativo), mas aquele com melhores aptidões para um determinado tipo de formação superior (donde o sistema de diferenciação). Isso é complementado com serviços de despiste vocacional e de orientação profissional.

Dos estudos e encontros preliminares à Conferência Mundial sobre o Ensino Superior, evidenciam-se dois grandes tipos de abordagem para a universidade do século XXI: a University-Company e a University-society (HIDALGO, 1996). No primeiro, o acesso é condicionado pelas necessidades de o mundo do trabalho ter profissionais qualificados e pelos fluxos de entrada e saída das universidades. Este tipo de abordagem implica uma selecção reguladora dos fluxos 
de entrada (perspectiva quantitativa). A questão da qualidade seria filtrada ao longo do percurso. A diminuição do número de entradas no ensino superior é, pois, o objectivo principal da selecção feita, o que se dá por meio dos numerus clausus e da manipulação do grau de dificuldade dos testes impostos. No segundo, a educação é considerada um direito fundamental do cidadão, sendo sua função a da formação de recursos humanos para responder não só às necessidades económicas, como também às sociais, políticas e culturais. Esta abordagem (recomendado pela UNESCO) impõe uma selecção baseada no mérito e na adequação do perfil do candidato. Trata-se de uma selecção que visa ao incremento da qualidade, não só pela obtenção de um nível de capacidades mais elevado, mas também pela melhor definição das aptidóes de cada um. Isto leva a considerar-se a importância de uma educação liberal, ${ }^{8}$ necessariamente transdisciplinar.

\section{A importância de uma educação liberal e transdisciplinar}

No mundo actual onde, mais do que os conteúdos, é necessário ensinar a flexibilidade de aprender a aprender e a adaptar-se, um ensino altamente científico e técnico é mau se não for contrabalançado com a chamada educação liberal. Podemos caracterizá-la por seu foco na

totalidade do desenvolvimento do indivíduo, para além da sua formação ocupacional. Ela inclui a civilização dos seus propósitos de vida, a refinação das suas reacçôes emocionais, o amadurecimento da sua compreensão da natureza das coisas de acordo com o melhor conhecimento do nosso tempo.

Estas palavras são de José Ortega e Gasset e foram proferidas em 1946! (The WORLD BANK, 2000).

Uma pessoa educada de forma liberal:

- consegue pensar e escrever de forma clara, eficaz e crítica;

- tem uma apreciação crítica dos modos como se obtém o conhecimento;

- tem um conhecimento alargado de outras culturas;

- pensa sobre problemas morais e éticos.
${ }^{8}$ Entende-se o termo liberal não no seu sentido político/económico mas no seu sentido original de "qualidade do que é livre". 
Uma educação liberal:

- conduz a uma cidadania responsável, comportamento ético, ambição educacional;

- promove a sociedade civil, o pensamento crítico e cria as condições necessárias a uma democracia participativa;

- reduz a drenagem de cérebros.

\section{Reflexões finais}

Embora se almeje que todo cidadão possa ter uma atitude transdisciplinar, decorre da análise do que é a transdisciplinaridade, que são condições necessárias: a) o conhecimento, quiçá domínio, de um número grande de disciplinas (para se fazer a interacção, o através e o para além delas, e b) a experiência vivida (para que se possa passar a outros níveis de realidade pelo exercício de um pensamento complexo e uma compreensão do que é um terceiro incluído).

Isso implica uma certa maturidade do cidadão e uma apreciável cultura geral ou elevado nível de conhecimentos. Talvez por isso a recomendação da UNESCO seja feita para as universidades. Pergunta-se então se os demais cidadãos, não universitários, não teriam de encarar a actual realidade de outra maneira. Claro que sim! E é dever de todos, cabendo à universidade um papel preponderante nesta questão: fazer mudar o paradigma educacional. Urge formar professores para o ensino básico e para o secundário, com visão transdisciplinar e aptos a ministrar uma educação liberal e consentânea com o futuro, numa nova ética da espécie humana que deve considerar a humanidade como comunidade planetária, constituindo uma cidadania terrestre (MORIN, 1999).

Cabo Verde, tendo já uma vivência transcultural, pode e desempenhará certamente um papel relevante na constituição dessa cidadania terrestre. A Universidade Jean Piaget de Cabo Verde, como a primeira universidade transdisciplinar do país e da região, irá certamente, por sua acção e pesquisa em curso, servir de digna referência nos próximos tempos. 


\begin{abstract}
Historical and geographic reasons transformed Cape Verde, across the last five centuries, into a place of civilizations' confluence and experimentation / acclimatization of the most diverse resources and ideas. This was expressed as an open society to the world, an economy of circulation and through the universal personality of the Capeverdian man. This strategic position in a globalized world requires a transdisciplinary vision from the citizen. Higher education is a privileged vehicle for such an end and under the scope of UNESCO's recommendations transdisciplinarity must be part of the new 21 st century university. The birth of a transdisciplinary university in Cape Verde looks like a natural thing. Such university was born in 2001(University Jean Piaget of Cape Verde) and already develops a transdisciplinary action and research pointed in this direction. However, Cape Verde's context of higher education lacks of bigger attention and the transdisciplinary vision would be more than necessary for a liberal education, for the benefit of a terrestrial citizenship.
\end{abstract}

\section{REFERÊNCIAS}

BRITO, Jorge Sousa. Une Approche pour l'Enseignement de la Chimie en Contexte Socioculturel Capverdien. $1^{\text {o }}$ Colóquio Mundial sobre a Transdisciplinaridade. Arrábida, Portugal, 1994. In: Transdisciplinarity / Transdisciplinarité. Lisboa: Hugin, 1999.

- Cartesianismo e Transdisciplinaridade no Ensino da Química, o caso dos alunos cabo-verdianos. - $1^{\text {as }}$ Conferências Internacionais de Epistemologia e Filosofia, mar. 1996 (Centro Internacional de Epistemologia e Reflexão Transdisciplinar (CIERT) do Instituto Piaget, Viseu. Aprendizagem / Desenvolvimento, n. 25-26, Instituto Piaget, 1997.

Que Ensino Superior para o Cabo Verde do Século XXI? In: O Desafio Africano. Venncio, José Carlos (Coord.). Lisboa: Vega, 1997.

. Por uma Universidade Transdisciplinar em Cabo Verde. Comunicação no colóquio L'Umanesimo Latino e L'Umanesimo Africano. Praia, Cabo Verde, jan. 2000.In: L'Umanesimo Latino e L'Umanesimo Africano. Treviso: Fondazione Cassamarca, 2000a.
KEY WORDS: transdisciplinarity; higher education; Cape Verde; University Jean Piaget; liberal education. 
O Acesso ao Ensino Superior: questôes da interface com o ensino secundário. Tema de abertura do painel "O Ensino Superior e a sua Articulação com o Ensino Secundário". X encontro da AULP, 25 a 28 abr. 2000. Universidade dos Açores. Ponta Delgada: Ediçōes da AULP, 2000b.

- Como Implementar o Ensino Superior em Cabo Verde (meios e estratégia) - número especial da revista CULTURA em comemoração do XXV Aniversário da Independência de Cabo Verde. Edição do Instituto Nacional de Investigação Cultural, 2001.

Cazenave, Michel; Nicolescu, Basarab. L'Homme, la science et la Nature regards transdisciplinaires. Collection Science et Conscience, Aix-en-Provence: Le Mail, 1944.

GIBBONS, Michael. L'enseignement supérieur au XXIème siècle. Education/The World Bank. Apresentado na Conferência Mundial sobre o Ensino Superior. Paris, 5 a 9 de out. 1998.

Hidalgo, J.C. Financing Higher Education. Havana: CresalC, Unesco, Apresentado na Conferência Regional em Políticas e Estratégias para a Transformação do Ensino Superior na América Latina e nas Caraíbas.

Judge, Antony J. N. Transdisciplinarity-3 as the mergence of patterned experience. $1^{\circ}$ Colóquio Mundial sobre a Transdisciplinaridade, Arrábida, Portugal, 1994. In: Transdisciplinarity / Transdisciplinarité. Lisboa: Hugin, 1999.

Morin, Edgar. Os sete saberes para a educação do futuro. Colecção Horizontes Pedagógicos, n. 87. Lisboa: Instituto Piaget, 2002. Introduction à la pensée complexe. Paris: ESF éditeur, 1990.

Réforme de pensée, transdisciplinarité, réforme de l'Université. Comunicação apresentada no congresso internacional sobre o tema "Quelle Université pour demain? Vers une évolution transdisciplinaire de l'Université", 30 abr.- 2 de maio 1997, Locarno, Suíça.

NicolesCu, Basarab. La transdisciplinarité, manifeste. Collection “Transdisciplinarité”, Paris: Éditions du Rocher, 1996. 
Éducation, transdisciplinarité et politique de civilisation. Comunicação apresentada na Conferência Mundial sobre o Ensino Superior. Paris, 5 a 9 out. 1998.

The World Bank. Higher Education in Developing Countries: Peril and Promise., Washington: The World Bank, 2000.

UNESCO. Déclaration mondiale sur l'enseignement supérieur pour le XXIe siècle et cadre d'action prioritaire pour le changement et le développement de l'enseignement supérieur. 1999. 
E
C
$\mathrm{C}$
$\mathrm{O}$
$\mathrm{S}$
$\mathrm{R}$
$\mathrm{E}$
$\mathrm{V}$.
$\mathrm{C}$
$\mathrm{I}$
$\mathrm{E}$
$\mathrm{N}$
$\mathrm{T}$.

$\mathrm{n} .1$
v. 5
jun.
2003

114 